\title{
Analysis of Programming Tools and Techniques in 3D Printing Technology
}

\author{
N.C. Brintha, J.T. Winowlin Jappes, P. Jothiraj
}

\begin{abstract}
This paper explains and analyses the additive manufacturing process from its varieties, types and usage of different programming tools. Printing process need to be selected mainly based on applications and the materials used for development. More applications of $3 D$ printing, were found to be in electronic industries which is mainly due to complexities in shape and size. Understanding of the prompt programming tool to be selected during complexity management is one of the major requirement. This requirement drives the research community from $3 D$ to $4 D$-Printing. Mainly, in $4 D$ printing concept, the object or the material system has the ability to change its form/function after it is being printed. The advantages and disadvantages of this technology towards the significant growth of applications were analyzed and presented in this paper.
\end{abstract}

Keywords : 3D Printing, 4D Printing, Applications, Growth Rate, Programming tools, Market.

\section{INTRODUCTION}

Now-a-days, 3D printing is revolutionizing product design and its development in many sectors. It is restructuring the ways in which a product is designed, developed and released. 3D printing which can also be referred as "Additive Manufacturing", is the process of creating a prototype from digital design [1]. It helps to build components layer by layer by using materials that are available in fine powdered form. All process are controlled and monitored by computer tools and software. This concept enables flexible and digital manufacturing operations and hence it is used in many applications [2].

The 3D printing process involves the following steps.

1) Preparation of object:

The first step is to prepare a digital model i.e., a 3D file of the structure to be generated. In-order to achieve this, most commonly CAD software or other relevant software's is used.

2) Conversion:

The CAD file is transformed in to an STL (stereolithography) or other equivalent file formats.

Revised Manuscript Received on December 16, 2019.

* Correspondence Author

N.C.Brintha*, Department of Computer Science and Engineering, Kalasalingam Academy of Research and Education, Tamilnadu, India. Email: n.c.brintha@klu.ac.in

J.T. Winowlin Jappes, Department of Mechanical Engineering, Kalasalingam Academy of Research and Education, Tamilnadu, India. Email: winowlin@klu.ac.in

P.Jothiraj, Department of Mechanical Engineering, Kalasalingam Academy of Research and Education, Tamilnadu, India.

Email: jothiraj@klu.ac.in
3) Manipulation:

When the intermediate file is ready, the size and orientation of the printing object is defined and fed to a computer which is connected to a $3 \mathrm{D}$ printer.

\section{4) Preparation of printer:}

Once after the digital component is complete, the other materials which are essential for the print operation like composite materials, plastics, binders, ceramic, etc. based on the job is selected.

\section{5) Construction:}

The time for printing varies depending on the complexity of object that is to be printed. Since the construction involves deposition of the material as thin layers, the printing span varies for each job.

6) Finishing:

After the construction step is complete, the printed object has to be removed carefully and may be subjected to post manufacturing operations like polishing, brushing and removal of dissolvable substances.

The major objective of this paper is to know the opportunities and challenges in 3D printing technology. This work presents the research challenges and benefits of $3 \mathrm{D}$ printing concepts and also describes the programming tools \& techniques used in this technology. The rest of the paper is organized as follows: Section 2 focuses on the literatures reviewed for understanding the challenges in this area. The techniques used and its benefits is described in Section 3 which is followed by analysis of programming tools, techniques and challenges Section 4. Section 5, finally concludes the work.

\section{BACKGROUND STUDY ON PRINTING TECHNOLOGIES}

Currently, a lot of printing technologies are available and each differs in the way of how the layers are constructed to create an object $[3,4]$. There are several rapid manufacturing process in $3 \mathrm{D}$ printing.

\section{1) Vat photopolymerisation:}

The photopolymers are hardened by continuous exposure to UV rays. The photopolymer which is in the form of a liquid resin is filled in to vat. Stereolithography (SLA) and Continuous Liquid Interface Production (CLIP) are the two common techniques in this approach.

Stereolithography is a process of creating models, patterns or prototypes using a photo chemical approach which makes the chemical molecule to form polymers through linkage. It is a common

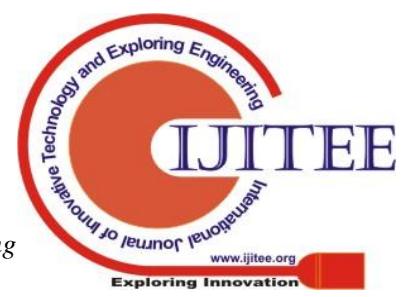


approach used in many applications of 3D printing.

Continuous Liquid Interface Production (CLIP) is a modern approach which is based on SLA but replacing SLA's nowadays due to its speed of processing. Unlike SLA, this approach does not pause layer by layer, the resign passes through a dead zone which lies above the oxygen preamble window.

\section{2) Material Jetting:}

The selected material is placed as layers one above another through a nozzle which is used to make a platform for the $3 \mathrm{D}$ object.

\section{3) Binder Jetting:}

In this process a powder base is dispersed equally in layers and a binder which is in the form of a liquid is poured through nozzles which glues the powder in to the shape of a programmed 3D object.

4) Material Extrusion:

It can be done using Fused Deposition Modelling (FDM) and Fused Filament Fabrication (FFF) technology.
FDM uses a filament or wire from a coil and helps in supply of material under control of the CAD program. FFF technology uses power bed fusion using either selective laser sintering (SLS) or direct metal laser sintering concept (DLS).

5) Sheet Lamination:

Sheets which are in the form of plastic, paper, metal or polymer are bonded together with huge external force.

6) Directed Energy Deposition:

This process is mostly used in large industries which is a form of rapid manufacturing. In this concept, a robotic arm which is capable of depositing material on the surface which is then followed by an energy source to form a solid object [6, 7]. A comparison on different technologies adopted in $3 \mathrm{D}$ printing is depicted in Table I

Table- I: Comparison of Different 3D Technologies

\begin{tabular}{|c|c|c|c|c|}
\hline TECHNOLOGY & ADVANTAGES & DISADVANTAGES & MATERIAL USED & $\begin{array}{l}\text { APPLICATION } \\
\text { AREA }\end{array}$ \\
\hline $\begin{array}{ll}\text { Selective } & \text { Laser } \\
\text { Sintering (SLS) [8] }\end{array}$ & $\begin{array}{l}\text { Durable complex part } \\
\text { construction, Modification to } \\
\text { parts is easy, Material Selection } \\
\text { flexibility, No post curing is } \\
\text { required, does not require } \\
\text { supporting structure }\end{array}$ & $\begin{array}{l}\text { Fabricated component may be } \\
\text { porus/rough, Polymer parts may cause } \\
\text { thermal distortion, machinery and } \\
\text { materials are expensive, additional } \\
\text { powder may harden at the border line }\end{array}$ & $\begin{array}{l}\text { Metal, glass, paper, } \\
\text { composites, ceramic }\end{array}$ & $\begin{array}{l}\text { Commercial products, } \\
\text { aerospace, automotive }\end{array}$ \\
\hline $\begin{array}{l}\text { Fused Deposition } \\
\text { Modelling (FDM) [9] }\end{array}$ & $\begin{array}{l}\text { Fast and inexpensive, process is } \\
\text { simple and has material } \\
\text { flexibility, parts have high } \\
\text { resolution }\end{array}$ & $\begin{array}{l}\text { Relatively low accuracy and poor } \\
\text { strength in vertical direction, } \\
\text { dimensional tolerances is not accurate }\end{array}$ & $\begin{array}{l}\text { Nylon, Polycarbonate, } \\
\text { Resin, ABS Filaments }\end{array}$ & $\begin{array}{l}\text { Automotive, Industry, } \\
\text { medicine, Aerospace }\end{array}$ \\
\hline $\begin{array}{l}\text { Stereolithography } \\
\text { (SLA) [10] }\end{array}$ & $\begin{array}{l}\text { Has high dimensional accuracy } \\
\text { and better surface finish, better } \\
\text { user support round the clock, } \\
\text { supports wide range of } \\
\text { materials }\end{array}$ & $\begin{array}{l}\text { Requires supporting structures, } \\
\text { post-processing, post-curing operations }\end{array}$ & $\begin{array}{l}\text { Composites and Liquid } \\
\text { photo polymer }\end{array}$ & $\begin{array}{l}\text { Aerospace, automotive } \\
\text { and customer goods }\end{array}$ \\
\hline $\begin{array}{l}\text { Photopolymer Jetting } \\
\text { (POLYJET) [11] }\end{array}$ & $\begin{array}{l}\text { Better precision and surface } \\
\text { finish, used with different } \\
\text { colors and materials, support } \\
\text { material need not be removed }\end{array}$ & Very slow build process & Wax, plastic, metal & $\begin{array}{l}\text { Medical devices and } \\
\text { prototypes }\end{array}$ \\
\hline $\begin{array}{l}\text { Material Jetting (MJ) } \\
{[12]}\end{array}$ & $\begin{array}{l}\text { Better accuracy and surface } \\
\text { finish, multiple material usage } \\
\text { and hands free removal of } \\
\text { support material }\end{array}$ & $\begin{array}{l}\text { Slower build process, Wax base } \\
\text { materials are limited }\end{array}$ & Wax & $\begin{array}{l}\text { Prototypes for } \\
\text { jewellery and medical } \\
\text { fields }\end{array}$ \\
\hline $\begin{array}{ll}\text { Selective } & \text { Laser } \\
\text { Melting (SLM) [13] }\end{array}$ & $\begin{array}{l}\text { Better speed and does not } \\
\text { require support, resistant to } \\
\text { heat and chemicals }\end{array}$ & $\begin{array}{l}\text { Limited precision and rough surface } \\
\text { finishing }\end{array}$ & $\begin{array}{l}\text { Metals like copper, } \\
\text { aluminium and tungsten }\end{array}$ & $\begin{array}{l}\text { Dentistry and } \\
\text { mechanical } \\
\text { components }\end{array}$ \\
\hline $\begin{array}{ll}\text { Electron } & \text { Beam } \\
\text { Melting (EBM) }[14]\end{array}$ & $\begin{array}{l}\text { Better printing speed and } \\
\text { subjected to lower distortion }\end{array}$ & $\begin{array}{l}\text { Finishing is not proper and care should } \\
\text { be taken when handling X-Ray }\end{array}$ & $\begin{array}{l}\text { Metal, Cobalt, chrome, } \\
\text { nickel }\end{array}$ & $\begin{array}{l}\text { Dentistry \& } \begin{array}{r}\text { other } \\
\text { medical models, } \\
\text { automotive }\end{array} \\
\end{array}$ \\
\hline $\begin{array}{lr}\text { Continuous } & \text { Fibre } \\
\text { Fabrication } & (\mathrm{CFF}) \\
{[15]} & \\
\end{array}$ & $\begin{array}{l}\text { Robust parts and no post curing } \\
\text { is needed, many materials can } \\
\text { be used }\end{array}$ & Limited fibre placement & $\begin{array}{l}\text { Plastics, carbon, } \\
\text { composites, nylon }\end{array}$ & Aerospace \\
\hline $\begin{array}{ll}\text { Digital } & \text { Light } \\
\text { Processing [16] } & \end{array}$ & $\begin{array}{l}\text { Build complex shapes and } \\
\text { sizes, better precision, } \\
\text { simultaneous production }\end{array}$ & $\begin{array}{l}\text { Limitation in product thickness and } \\
\text { less range of materials }\end{array}$ & $\begin{array}{l}\text { Liquid photopolymer, } \\
\text { Liquid Crystals, Digital } \\
\text { Micro mirror Device, } \\
\text { Integrator, liquid crystal } \\
\text { display, Projectors, resin } \\
\end{array}$ & $\begin{array}{lr}\text { DLP projectors, } \\
\text { Holographic } & \text { Data } \\
\text { Storage, } & \text { PCB } \\
\text { manufacturing } & \end{array}$ \\
\hline $\begin{array}{l}\text { Selective Deposition } \\
\text { Lamination [17] }\end{array}$ & $\begin{array}{l}\text { Quick in making bigger parts, } \\
\text { less expensive and non-toxic }\end{array}$ & $\begin{array}{l}\text { Low accuracy and non-homogeneous } \\
\text { parts }\end{array}$ & $\begin{array}{l}\text { Paper, plastic, resin, } \\
\text { laminates, ceramics, } \\
\text { composites }\end{array}$ & $\begin{array}{l}\text { Manufacturing and } \\
\text { industrial applications }\end{array}$ \\
\hline
\end{tabular}




\section{TRENDS AND APPLICATION OF 3D PRINTING}

Additive Manufacturing growth has increased nearly $62 \%$ over the past two years as shown in Fig. 1 (Wohler's Report, 2019). Industries have profited by about $\$ 200$ million by producing $\$ 10$ billion products and services. The factors that influences this growth are design, training \& education, post processing automation, good supply chains, investments, partnership \& collaborations, corporate excellence and interconnectivity.

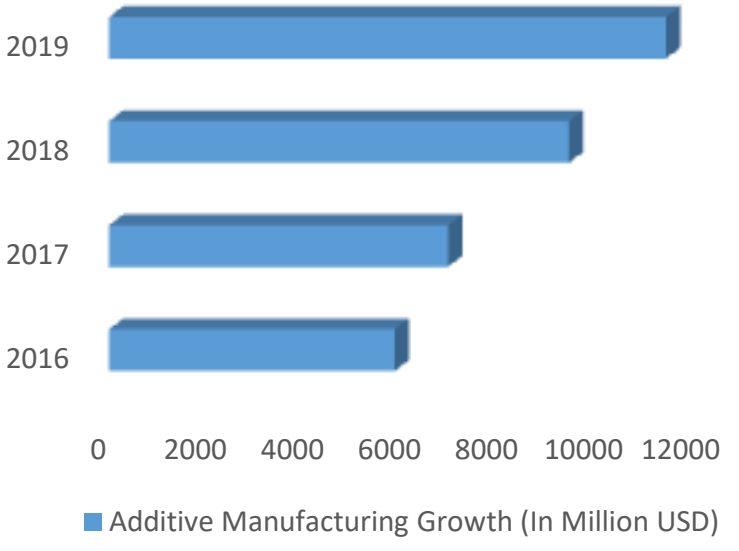

Fig. 1.Growth Rate of AM in Past 4 years

Most of the sectors like medical, automotive and aerospace are expected to use the 3D/4D printing technology by $51 \%$ in 2025 . By 2025 , the growth rate is predicted to about $\$ 21.50$ Billion. The prediction on percentile of growth of 3D/4D printing in various sectors is illustrated in Fig 2. This is about to increase with a Compound Annual Growth Rate (CAGR) of $11 \%$ [19].

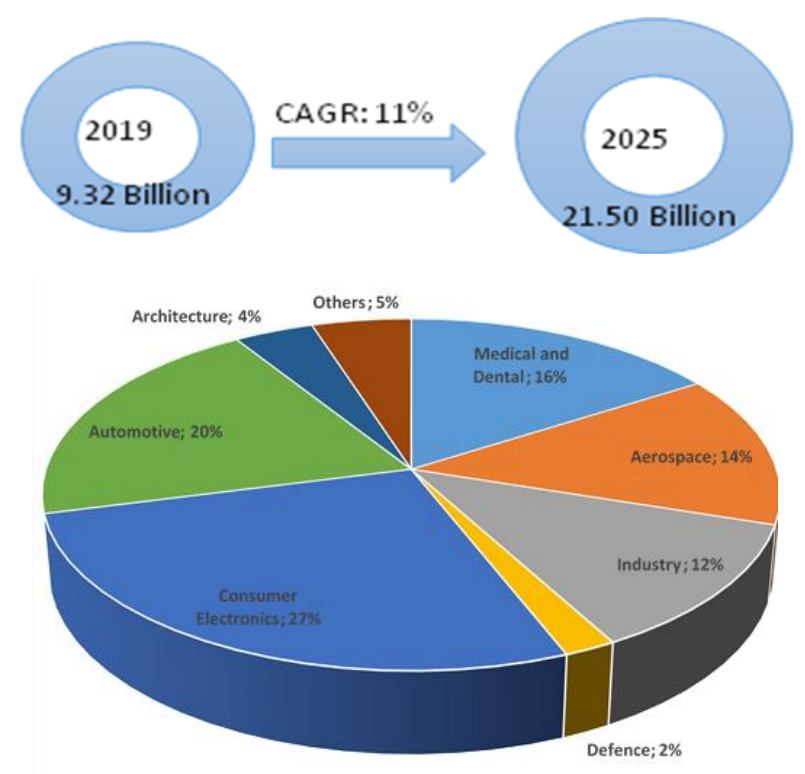

Fig. 2. Growth Rate of 3D technology in Several Applications (frost \& Sullivan, 2016)

\section{ANALYSIS OF PROGRAMMING TOOLS AND TECHNNIQUES}

Programming in 3D printing is analysed in to two categories: $3 \mathrm{D}$ graphics programming and 3D printer programming [20,

21]. Variety of software's are required during each phase of $3 \mathrm{D}$ printing till the creation of $3 \mathrm{D}$ object. The $3 \mathrm{D}$ object is created by applying 3 phases: Model Designing, Testing/Repair of G-code and Generation of G-Code (Printing).

\section{A. Model Designing}

A 3D object is created using modelling, scanning and downloading from online repositories

1) Modelling: This tool is used for creating/drawing the 3D model and user can make their section an appropriate tool based on their application needs like complexity, version etc.

- Tinkercad (Beginners) - This is a popular user friendly educational tool used by designers and educators. The objects are saved as STL files and it offers solid/box model parameters.

- Sketchup (Beginner and Intermediate) - It is a powerful modelling tool available for both beginners and intermediate users. It has a lot of built-in models.

- Free CAD (Intermediate) - It is used for parametric modelling.

- AutoCAD (Intermediate \& Professional) - Offers free sophisticated tools for both 2D and 3D modelling. It is used much for educational purposes.

- OnShape (Professional) - Cloud based CAD platform. Offers more flexibility and concurrency in applications.

- Blender (Professional)-Open source used for variety of applications like 3D modelling, simulation, texturing, skinning, animation and especially video editing.

- Fusion 360 (Intermediate \& Professional) - Next level software which is cloud based and is more flexible than several other modelling software packages.

- Morphi App (Beginner) - Enables users to create 3D models independent of their skill level.

- Rhino 3D (Intermediate \& Professional) - Stand-alone tool for variety of applications due to low cost, diversity, convertor of over 30 file formats.

- 3ds Max (Professional) - Provides modelling, simulation support, animation, rendering for motion graphics applications like games, film etc.

- Cinema 4D (Professional) - Used for advanced 3D graphics.

- Maya (Processional) - This is a computer graphics software for animation, modelling, simulation and rendering. It is used for interactive $3 \mathrm{D}$ applications.

- 3D Slash (Beginners and Intermediate) - It offers fun and easy to use interface. It is used for working with high level of precision.

- 123 Design (Intermediate) - It is used to create and edit 3D models easily. This is ideal for performing collaborative works.

- Inventor (Intermediate \& Professional) - Provides a variety of tools for automation and simulation. It has different packages with different levels of proficiency.

- Wings 3D (Professional) - It has advanced modelling tools which are free from complex representations.

- Auto desk Revit (Intermediate \& Professional) Coordinated and consistent object modelling approach. 
- Solid Works (Intermediate)-This enables rapid creation of 3D parts, drawings.

- Catia (Professionals) - Best software solution used to design, analyse, simulate and manufacture products. It is used in variety of industrial sectors.

2) Scanning: This enables to capture the digital copy of the physical real world object. 3D scanning is classified based on 3 technologies: laser triangulation, scan by time-of-flight and scan by phase field. Some example scanning tools are Kinect, xyz printing, Sense, Structure etc.

3) Downloading: The 3D models can be collected and downloaded from several repositories and it may be readily available for printing with small correction if needed.

\section{B. Programs for Testing/Repair}

Before the final phase i.e. printing phase, the 3D model has to be analysed for errors and failures. Some example tools for repairing the modelled object are Autodesk Netfabb, Meshlab, Autodesk Meshmixer etc.

\section{Programs for Generation of G-Code}

G-Code or Geometric-Code is a programming language that instructs the printer on when, where, how much to move, how fast/slow to move, what to extrude during the printing process.

G-Code can be generated using several software's among that Cura is a specialized software used for G Code generation. Some of the printing software's are used for printing is as follows.

- Cura (Beginner) - This is a benchmark Slicer software optimum for printing and can be extended if needed. It provides an easy to use interface.

- MatterControl 2.0 (Beginner) - Slicer used for desktop applications, 3D Printer Host and provides an interface is properly structured.

- 3DPrinterOS (Beginner) - Provides Cloud based control and App based plug-in, STL tools and printer host.

- CraftWare (Beginner \& Intermediate)-Free, fast and easy to use slicer software which provides better Gcode visualizer and manual support.

- KISSlicer (Intermediate) - Cross Platform gcode generator.

- Repetier Host (Intermediate) - This acts as a front end for 3D printer. Uses Slic3r as default slicing engine also has Skeinforge.

- Slic3r (Intermediate and Professional) - Slicer program is used for preparing 3D models. Prints with multiple extruders, graphic and command line interface, simultaneous printing of multiple images etc.

-

\section{GROWTH OF 3D PRINTING TOWARDS 4D PRINTING}

Any technology that emerges has both positive and negative impacts. 3D printing technology has invaded many industrial sectors, medical field, military, education, aerospace, construction etc. The growth of $3 \mathrm{D}$ to $4 \mathrm{D}$ technology has also several advantages and on the other side it brings out a variety of technical and legal challenges [22]. This section describes the strengths, weakness and challenges of both technology. 4D printing addresses certain challenges in $3 \mathrm{D}$ printing for wide adoption in industries. In 4D printing concept, the object or the material system has the ability to change its form/function after it is being printed [23].

\section{A. SWOT Analysis of 3D Printing Technology}

SWOT analysis, a strategic planning technique, is analyzed for 3D printing and the details are illustrated as follows [24].

1) Strengths and Weakness

The various strengths of $3 \mathrm{D}$ printing technology is as follows:

- With all the resources available, any design (simple/complex) can be printed and thus provides customized products.

- Better Productivity and large number of prototypes.

- This provides an affordable technique even though the initial cost may be high.

- Reduced Storage Cost and better employment opportunities for designers.

- Among several applications, Bio-printing application of 3D technology is a breakthrough in medical field.

- They can produce better products with high quality.

- Helps in development of innovated products

The various weakness of $3 \mathrm{D}$ printing technology is as follows:

- Size of the created object is small.

- Usage of limited raw materials which may make certain material to become scarce.

- Ability to counterfeit products easily without copyrights.

- More energy Consumption

- Some printers have harmful emissions.

- Illegal usage by criminal organization leads to production of dangerous weapons.

- Expensive in some cases.

- Requires proper skills for usage

2) Opportunities and Threats

The opportunities for improvement are as follows:

- 3D printers is about to invade homes (desktop computers), shops and factories.

- Advances in production of raw materials used.

- Better Resolution accuracy and speed.

- Reduction in time and cost by 10 times for production of complicated parts.

- Create a wide variety of electronic products.

- Transition to 4D printing.

The social, economic and personal threats due to usage of 3D printing is as follows.

- Hackers could intrude and may cause damage

- Usage of additive manufacturing technology may threaten jobs.

- Risk in property and bodily injury (medical application)

- Cyber and Intellectual Property Risk (IPR).

- Frequent up-gradation and compatibility issues of machines. 
- Ethical issues in object model.

- Environmental issues

\section{B. SWOT Analysis of 4D Printing Technology}

Similar to the above discussion SWOT analysis is carried out for 4D printing. 4D printing is the next generation of 3D concept in which the properties and characteristics of the created object has the ability to change its shape/form after manufacturing.

\section{1) Strengths and Weakness (4D Printing)}

The various strength of $4 \mathrm{D}$ printing is explained as follows:

- Usage of smart materials.

- Ability to reshape after printing i.e. SME (Shape Memory Effect).

- Multiple materials and multiple colors can be used.

- Positive growth in market place.

- Speed and efficiency of printing.

- Smart materials which has the ability to be reprogrammed.

- Reduction in storage costs

The weakness in implementing 4D technology are as follows:

- Some of the disadvantages of 3D printing also applies to 4D printing. It's an evolving domain with new functionality and modifications.

- New technology so requires expertise.

- Material cost is expensive and limited.

- Requires expensive hardware.

- Very high initial cost.

- Still in the adolescence stage of science, so has to be improved

4D printing technology promotes several opportunistic challenges towards growth which are discussed as follows:

- Improves implantation of organs in medical field

- Positive growth of market size.

- Useful in extreme places

- Interactive applications like medical implantation, self-assembling construction, and soft robotics are some of its applications.

The major threats to this sector is as follows:

- Environment and public safety related problems.

- Intellectual Property Risk (IPR) issues.

- Compatibility issues in machines.

- Loss of job opportunities for people.

- Cyber-crime related issues.

\section{Growth statistics of 3D and 4D Printing}

Based on the Marketsandmarkets report, the growth rate of $3 \mathrm{D}$ printing market is about to reach 30.19 Billion USD by 2022 at an annual growth of $28.5 \%$ as shown in Table II. It is expected that this concept will flourish much more in manufacturing, medical field, aerospace, defense and consumer products [25]. It is estimated that by 2022, the market size growth is about 30.19 billion USD.

Likewise, 4D printing market is about to successful by 2020 because of its advanced programming and efficiency [26]. These industries are expected to have a compound annual growth of $42.5 \%$ between 2019 and 2025 and expected to reach 537.8 million as shown in Table II.
Table- II: Comparison of 3D/4D printing market size growth rate (USD million)

\begin{tabular}{|l|l|l|}
\hline \multirow{2}{*}{ YEAR } & \multicolumn{2}{|l|}{ MARKET SIZE (USD MILLION) } \\
\cline { 2 - 3 } & 3D Printing & 4D Printing \\
\hline 2016 & 6.17 & - \\
\hline 2017 & 8.62 & - \\
\hline 2018 & 11.08 & - \\
\hline 2019 & 14.23 & 64.2 \\
\hline 2020 & 18.29 & 91.49 \\
\hline 2021 & 23.5 & 130.39 \\
\hline 2022 & 30.19 & 185.81 \\
\hline 2023 & - & 264.8 \\
\hline 2024 & - & 377.38 \\
\hline 2025 & - & 537.8 \\
\hline
\end{tabular}

\section{CONCLUSION}

This paper has reviewed about the possible 3D-Printing techniques towards application with the understanding of programming skill for future growth of its transition. Also it analysed the strengths and weakness towards the growth of 4D-Printing. Opportunities for researchers were found to be bright with proper understanding of the effects of different programming in complex geometrics. Vacuum in research could be identified using varieties of materials for printing. 4D-Printing create huge openings for researchers towards printing of materials with phase change capability. The cost of these techniques is found to be a limiting factor.

\section{REFERENCES}

1. J. Flavio Craveiro, Jose Pinto Duarte, Helena Bartolo, Paulo Jorge Bartolo., "Additive manufacturing as an enabling technology for digital construction: A perspective on Construction 4.0," Journal of Automation in Construction, Vol. 03, No. 1, pp. 251-267, 2019.

2. Abdulrahman Al-Ahmari, Wadea Ameen, Mustufa Haider Abidi, Syed Hammad Mian., "Evaluation of 3D printing approach for manual assembly training," International Journal of Industrial Ergonomics, Vol. 66, pp. 57-62, 2018.

3. Choi, Jae-Won, and Ho-Chan Kim., "3D Printing Technologies - A Review," Journal of the Korean Society of Manufacturing Process Engineers, Vol. 14, No. 3, pp. 1-8, 2015.

4. Dara G.Schniederjans., "Adoption of 3D-printing technologies in manufacturing: A survey analysis," International Journal of Production Economics, Vol. 183, Part A, pp. 287-298, 2017.

5. Davoudinejad, Ali C. Díaz Perez, Lucia Quagliotti, Danilo Pedersen, David Albajez, Jose Yagüe-Fabra, Jose Tosello, Guido., "Additive manufacturing with vat polymerization method for precision polymer micro components production," Procedia CIRP, Vol.75, pp. 98-102, 2018

6. Shiwpursad, Jasveer \& Jianbin, Xue., "Comparison of Different Types of 3D Printing Technologies," International Journal of Scientific and Research Publications (IJSRP), Vol.8, No. 4, 2018.

7. Zhou Yufeng., "The recent development and applications of fluidic channels by 3D printing," Journal of Biomedical Science, Vol. 24, No. 1, pp. 1-22, 2017.

8. Aoulaiche Mokrane, Mhamed Boutaous, Shihe Xin., "Process of selective laser sintering of polymer powders: Modeling, simulation, and validation," Comptes Rendus Mecanique, Vol. 346, No 11, pp. 1087-1103, 2018.

9. E. Carlier, S. Marquette, C. Peerboom, L. Denis, J. Goole., "Investigation of the parameters used in fused deposition modeling of poly(lactic acid) to optimize 3D printing sessions," International Journal of Pharmaceutics, Vol. 565, No.2, pp. 367-377, 2019.

10. Despa V, Gheorghe I.Gh., "Study of Selective Laser Sintering -A Qualitative And Objective Approach," The Scientific Bulletin of Valahia University - Materials and Mechanics, No. 6, 2011.

11. Hang-NgaMai, MSaKyu-BokLee, 
Du-HyeongLee., "Fit of interim crowns fabricated using photopolymer-jetting 3D printing," The Journal of Prosthetic Dentistry, Vol. 118, No. 2, pp. 208-215, 2017.

12. Ming-Jong Tsai, Che-Wei Mei, Yih-Lin Cheng, Freeman Chen, Zhao-Yen Hu, Kuan-Chi Huang., "A study of a material jetting based color $3 \mathrm{~d}$ printing system by using multiple piezoelectric heads," International Conference on Machine Learning and Cybernetics (ICMLC), July 2017.

13. Y. Igor., "Selective laser melting: Direct manufacturing of 3D-objects by selective laser melting of metal powders", 2009.

14. Basak, Soumya., "A Technical Report on Electron Beam Melting (EBM): An Additive Manufacturing (AM) Technique," 2016.

15. H. Zhanghao, T. Xiaoyong, Z. Junkang, L. Dichen., "3D Printed Continuous Fibre Reinforced Composite Corrugated Structure," Composite Structures, Vol.184. pp. 1005-1010, 2017.

16. M. Quanyi, W. Lei, D. Conner, K. Xiao, D. Feng, Z. Zhong, J. Qi, W. Tiejun., "Digital light processing 3D printing of conductive complex structures," Additive Manufacturing, Vol.18, pp. 74-83 2017.

17. Ze-Xian Low, Yen Thien Chua, Brian Michael Ray, Davide Mattia, Ian Saxley Metcalfe, Darrell Alec Patterson., "Perspective on 3D printing of separation membranes and comparison to related unconventional fabrication techniques," Journal of Membrane Scien-ce, Vol. 523, No. 1, pp. 596-613, 2017.

18. Wohlers Associates, "3D Printing and Additive Manufacturing State of the Industry," Annual Worldwide Progress Report, Report 2019, https://wohlersassociates.com/2019report.htm,

ISBN 978-0-9913332-5-7, 2019.

19. Frost \& Sullivan., "Advances in 4D Printing (Technical Insights)," Nine Pronged Technology Evaluation-Next Paradigm in Manufacturing, 2014, pp. 1-16.

20. Kiril Vidimce, Szu-Po Wang, Jonathan Ragan-Kelley, and Wojciech Matusik., "OpenFab: A Programmable Pipeline for Multi-material Fabrication," ACM Trans. Graph, Vol. 32, No. 4, pp. 1- 136, July 2013

21. Zhenmin Li, Shan Lu, Suvda Myagmar, and Yuanyuan Zhou. ,"Cp-miner: A tool for finding copy-paste and related bugs in operating system code," In Proceedings of the 6th Conference on Symposium on Operating Systems Design \& Implementation, OSDI'04, International Journal of Innovative and Applied Research, Vol. 6, pp. 23- 32, 2014

22. Nkomo, Nkosilathi., "A Review of 4D Printing Technology and Future Trends," Eleventh South African Conference on Computational and Applied Mechanics, At Vanderbijlpark, South Africa, 2018.

23. Campbell. T.A, Tibbits. S. and Garrett, B., "The next wave: 4D printing programming the material world," Atlantic Council, Brent Scowcroft Center on International Security, 2015

24. Osita, Ifediora., "Organization's stability and productivity: the role of SWOT analysis an acronym for strength, weakness, opportunities and threat", International Journal of Innovative and Applied Research, Vol. 2, pp. 23- 32, 2014.

25. Mitchell, U. Lafont, M. Hołyńska, C. Semprimoschnig., "Additive manufacturing - A review of 4D printing and future applications," Additive Manufacturing, Vol. 24, Pages 606-626, December 2018.

26. Marketsandmarkets., "3D Printing Market by Offering (Printer, Material, Software, Service), Process (Binder Jetting, Direct Energy Deposition, Material Extrusion, Material Jetting, Powder Bed Fusion), Application, Vertical, Technology, and Geography - Global Forecast to $2024 ", 2016$.

\section{AUTHORS PROFILE}

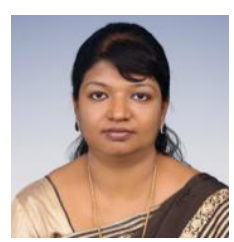

Brintha N C graduated in 2002 from Manonmaniam Sunderanar University, India. In 2006, she received her M.E Degree with distinction in Computer Science and Engineering from A.K.C.E, Anna University, Chennai. She completed her Ph.D degree in 2018 in the area of Cloud Manufacturing under Anna University, Chennai. Currently, she is working as Associate professor/ CSE in Kalasalingam Academy of Research and Education, India. Her research interests include Cloud computing, Optimization, Scheduling, Cloud Manufacturing and so forth.

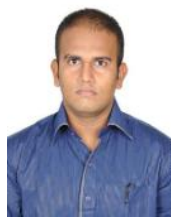

Winowlin Jappes J $\mathbf{T}$ graduated in 1997 from Manonmaniam Sunderanar University, India in Mechanical Engineering. In 1999, he has completed his masters in Production Engineering from Annamalai
University. He completed his Ph.D degree in 2004 in the area of Composite Deposition at Indian Institute of Technology Madras, Chennai. He has completed three DST funded research projects and published more than 125 research articles which includes 65 International Journal papers. Currently, he is working as Senior Professor in Kalasalingam University, India. His research interests includes high performance composite materials, machining of hard materials, optimization techniques, etc. At present, he is working as Professor and Dean, School of Automotive and Mechanical Engineering, Kalasalingam Academy of Research and Education, India.

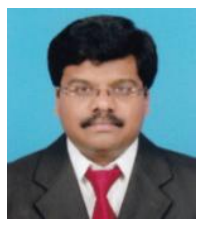

Jothiraj Palaniappan has completed his bachelor's degree in the department of Mechanical Engineering under Anna University with First rank and gold medal, proceeded with the degree of masters under the Manufacturing Engineering with First Rank and Gold medal. He is being nominated and selected as the Mentor for change under the NITI-Ayog, Govt. of India for AIM. Has published two papers in peer reviewed journals. Active member in the IAEng. Research interest being inclined towards the advanced materials as shape memory alloys and phase changing materials. 